\title{
TAVARES, Breitner. 2012. Na quebrada, a parceria é mais forte: Jovens, vínculos afetivos e reconhecimento na periferia. São Paulo/Brasília, Annablume/Fundo de Apoio a Cultura do Distrito Federal. 296 pp.
}

Soraya Fleischer (UNB)
A Ceilândia é uma das 24 regiões administrativas do Distrito Federal. Os dados oficiais, geralmente subestimados, atestam que havia em 2010 quase 400 mil habitantes na cidade (Pesquisa Distrital por Amostra de Domicílios, 2011 :24). 25\% dessa população eram jovens entre 10 e 19 anos (idem, 25). É considerada, depois de São Paulo, a cidade com maior contingente migratório do Nordeste brasileiro e guarda uma diversidade social e econômica impressionante. Ainda assim, a Ceilândia só vagarosamente tem interessado sociólogos e antropólogos. Além dos trabalhos de Mara Resende (Ceilândia em movimento, de 1985) e de Breitner Tavares, em pesquisa anterior (Feira do rolo. Na pedagogia da malandragem: memória e representações sociais no espaço urbano de Ceilândia/DF, de 2005), quase não se encontram reflexões das Ciências Sociais sobre essa cidade instigadora.

Contudo, neste ano, felizmente fomos brindados com mais uma pesquisa sobre a Ceilândia no livro recém-lançado pelo sociólogo Breitner Tavares. Este é um estudo sobre juventude, "com ênfase no estilo de vida hip-hop na periferia urbana do Distrito Federal" (:15). De forma interessante, ele alerta que "a juventude redefine, sob uma nova ótica, a própria maneira de compreender o que significa 'ser urbano' na contemporaneidade" (:16). Em notas esparsas e módicas ao longo do livro, aos poucos descobrimos que na Ceilândia o autor viveu na infância, foi professor de ensino fundamental, médio e EJA na juventude e agora retorna como adulto e professor de ensino superior no campus da Universidade de Brasília instalado nessa cidade.

O trabalho de campo, realizado entre 2005 e 2009, compreendeu tanto pesquisa histórica em jornais locais (entre 1985 e 1994) quanto pesquisa qualitativa e presencial. “Quinze grupos de discussão com aproximadamente cinquenta e cinco jovens, organizados em grupos de rap e street dance" (:37) foram contatados. Estes jovens tinham, à época, entre 17 e 27 anos. Destes grupos, ele escolheu quatro para realizar histórias de vida, questionários e observação participante. 
O hip-hop não está ligado somente aos grupos subalternizados e os movimentos juvenis reivindicatórios, mas, como mostra Tavares, a todo um mercado de bens de consumo simbólicos e materiais em meio às grandes metrópoles brasileiras. O hip-hop enseja uma intensa discussão sobre "centro/periferia" e, num olhar rápido demais, poderíamos facilmente identificar a Ceilândia como uma periferia passiva, invisibilizada e inexpressiva. De forma inversa, Tavares nos mostra como a Ceilândia foi identificada como uma fonte produtora do hip-hop, nos idos dos anos 1980, ainda que sua condição de periferia simbólica e geográfica tenha contribuído para certo "glamour do gueto". Tudo começou com os sons, festinhas "que ocorriam em casas de particulares aos sábados", e as ruas de lazer, sociabilidade de rua nas tardes de domingo, onde os jovens "se encontravam para dançar break e funk" com a trilha sonora proporcionada pelas equipes de som e DJs (:21). Já nos anos 1990, a comicidade das melôs passou à conscientização da juventude proposta pelos raps. Nestas letras mais contundentes, como é ilustrado na música "Sub-raça" do famoso grupo Câmbio Negro que ajudou a catapultar a Ceilândia ao cenário do rap nacional, a exclusão social e racial vivida cotidianamente por esses jovens ceilandenses fica explícita. É nessa época, anuncia Tavares, que a Ceilândia passou pela primeira vez dos cadernos de polícia e esporte aos cadernos de cultura nos jornais da cidade. Assim, esse rap, pela qualidade musical e pelo alcance nacional, foi um fenômeno importante na construção de uma imagem mais heterogênea e menos estigmatizada desta "cidade satélite" do Distrito Federal.

Embora este capítulo inicial seja de grande valia, sobretudo para situar os leitores nos processos e mudanças do Distrito Federal, há um gap entre os anos 1990 e os anos 2000, quando se localiza a interação do autor com os rappers da Ceilândia. Além disso, nessa história há uma profusão de nomes de bandas, discos, boates, produtoras etc., sem que tenha sido aproveitada para entender o cenário sociocultural do hip-hop na cidade.

Os entrevistados vivem constrangimentos de ordem estrutural por serem jovens, pobres, negros, pouco escolarizados e músicos do hip-hop. Aprendemos que o material de campo - transformada em potente teoria nativa - revela as várias caras da "violência". Esta pode estar relacionada ao fato de o jovem vir de uma família nordestina e carregar seu sotaque e fenotipia, por rechaço amoroso, por ausência paterna, pelo estigma de ter irmãos ou parentes presos, por ter trabalhado já na infância, pelo disciplinamento escolar, pela austeridade policial - tida como "mais agressiva na Ceilândia", segundo os entrevistados (:261). O constrangimento por seguranças de lojas e shoppings, vendedores ou transeuntes é recorrente na circulação desses rappers pelo Distrito Federal, devido a suas correntes, bonés, tênis e roupas folgadas (identificadas por eles, com autoironia, como o estilo fragrante). Ao longo de todo o livro, vemos que muito da violência deriva simplesmente do fato de serem da Ceilândia.

A partir da experiência de preconceito social, os quatro grupos de rap declaram "ajudar o próximo" e "lutar pela periferia" (:109) ou "sua comunidade" (:91). Segundo Tavares, "ser rapper implica em ser solidário, no sentido de compartilhar os valores da positividade para sua comunidade local" (idem). Há um foco social nos outros jovens, sobretudo: "O envolvimento com o rap é definido pelo grupo como um meio de alertar outros jovens quanto à luta por justiça. Eles num tom de riso, dizem que se tornaram os 'advogados dos muleques', ao se referirem à importância de não se permitirem ser humilhados e viabilizarem meios para a denúncia das injustiças" (:146). Assim, colocado de forma eficiente e sintética pelo autor, "o rap é definido simultaneamente como diagnóstico, projeto e o próprio 
sentido da existência do grupo" (:103). Mas Tavares também mostra como estes grupos e seus fãs criam novos mecanismos de distinção em relação ao próprio bairro, à cidade da Ceilândia, à periferia. Há os "pobres", mas há os "mais pobres" ainda, com os quais os rappers nem sempre se identificam, valorizam e entoam em suas músicas. O reconhecimento público ajuda a criar novas clivagens, subdividindo e por vezes hierarquizando as periferias.

Para além da indústria cultural e da contestação social, Tavares, assim como a pesquisa de Fernanda Noronha em sua pesquisa em São Paulo (“Onde estão as b.girls? A pesquisa antropológica numa roda de break", publicado no livro Entre saias justas e jogos de cintura, de 2007), aborda os relacionamentos, a sexualidade e as relações de gênero do mundo do rap. E explica: A "misoginia e o sexismo, enquanto valores masculinos, assumidos pelos grupos, não inviabilizam a construção de discursos afetivos em que as mulheres estabeleçam outras diretrizes, seja no sentido de uma inversão de poder patriarcal ou mesmo na construção de novas utopias que possam interferir na solução de problemas enfrentados pela juventude" (:160). O autor percebe que seus entrevistados sustentam uma idealização bastante conservadora para o relacionamento (:186), onde viver no frevo ou viver zanzando (vários relacionamentos simultâneos ou vários subsequentes, respectivamente) é tão valorizado quanto sonhar em estar parado (o vínculo monogâmico).

Há um paralelo entre o regramento trazido pelo rap e os relacionamentos amorosos, como lembrou Amauri: “Eu sempre tô visando o rap mas como eu te falei, na minha vida ela [a namorada] veio como o rap, o rap veio para mim ficar mais dentro de casa, mais atento, mais esperto" (:194). Entre uma mulher braba ou carinhosa, surge um terceiro tipo, a mulher que trabalha a cabeça do seu companheiro, influenciando positivamente sua vida e valorizando sua natureza, suas escolhas, etc. Tavares explica que "o relacionamento possui a capacidade de redefinição do papel masculino às vezes inserido no contexto de conflitos com outros jovens e grupos rivais que promovem a 'guerra'. A mulher aqui tem a capacidade de 'mudar a cabeça' do homem na medida em que estes escolhem enfrentar os dilemas de seu tempo construído intersubjetivamente, que é também capaz de gerar a transformação" (:212).

Por fim, há alguns aspectos menos consistentes na obra. O uso de uma abreviação para cada pseudônimo tornou o texto mais hermético e poluído visualmente, exigindo a consulta constante da legenda ao final do livro. Além disso, a longa descrição dos grupos poderia, ao final, ter sido sintetizada em uma tabela. Embora o uso de longos trechos de depoimentos seja uma prática corriqueira nas Ciências Sociais, provocou-me certo estranhamento a inserção de uma série de "códigos de transcrição", que interrompem muito a leitura. Talvez esses marcadores revelem informações sobre os grupos entrevistados, que têm familiaridade com grafites e comunicação via mensagens de celulares e redes sociais. Teria sido interessante perceber a relação entre essa escolha do autor e as formas expressivas das pessoas com quem ele conviveu em campo.

O código de transcrição "Y", que na legenda figura como "entrevistador", é usado em metade do livro. Na segunda metade, em uma discreta nota de rodapé, ele muda o registro de sua presença, deixando finalmente a terceira pessoa: "Eventualmente farei uso dos verbos em primeira pessoa para tentar recriar a atmosfera de intimidade estabelecida durante a pesquisa de campo" (:166, nota 2). Por que não manter esse tom de intimidade ao longo de todo o livro, já que a "atmosfera" do campo, desde o início, é revelada como um recurso discursivo 
importante no estabelecimento de empatia com os leitores? Parece que a primeira pessoa teria sido mais coerente com a metodologia escolhida e com as demandas de envolvimento que o próprio campo impôs ao pesquisador.

Ao final do livro, entendemos que Tavares nos diz que esses "jovens definem a 'periferia' como espaço em que prevalecem as relações vicinais e seus consequentes vínculos afetivos" (:270). Mais do que com o rap e uma Sociologia da Arte e da Música, Tavares nos brinda com uma sociohistória da Ceilândia, e com um retrato contemporâneo do que é ser jovem na "periferia" da capital federal - servindo, claro, para avançar a produção das ciências sociais na região e também como retorno provocador e reflexivo para os jovens envolvidos na pesquisa. Ao longo de sua pesquisa, portanto, ele suplanta a espetacularização da juventude e também a mitificação da pobreza, e nos mostra com beleza sociológica como o rap é uma ferramenta eficiente na consolidação desses vínculos, comprovando o sugestivo título da obra, segundo o qual "na quebrada, a parceria é mais forte". 